\title{
EXPERIMENTAL INVESTIGATION OF AIR-WATER TWO-PHASE FLOW REGIMES IN A HORIZONTAL WAVY MICRO-CHANNEL
}

\author{
DOAA AWAD, ABDUL RAFEY SIDDIQUI, YASSER AL-HAMIDI, \\ MOHAMMAD AZIZUR RAHMAN \& IBRAHIM HASSAN \\ Texas A\&M University, Qatar
}

\begin{abstract}
The objective of this experimental study was to develop a flow regime map for two-phase air-water flow within a wavy horizontal micro-channel. The water flow rates were varied from $29.1 \mathrm{~cm}^{3} / \mathrm{min}$ to $218 \mathrm{~cm}^{3} / \mathrm{min}$, and the air flow rate was varied from $313.3 \mathrm{~cm}^{3} / \mathrm{min}$ to $2350 \mathrm{~cm}^{3} / \mathrm{min}$. The variations culminated in a total of 63 different data points. The captured video of the flow was analyzed visually, and the flow regime was determined. This was repeated for each data point to ensure experimental repeatability. Seven different flow regimes were observed within this micro-channel, which were annular flow, bubbly flow, churn (or semi-annular) flow, plug flow, slug flow, stratified flow, and wavy flow. The data points were plotted on a flow regime chart. This map, which pertains to horizontal flow within wavy micro-channels, was also compared against flow regime maps for straight horizontal and vertical micro-channels.

Keywords: two-phase flow, wavy microchannel, visualization, flow regimes, high-speed camera.
\end{abstract}

\section{INTRODUCTION}

Two-phase flow in micro-channels contributes significantly to several industries ranging from engineering applications to medical applications. Several devices that use two-phase flow include heat exchangers, medical equipment, and micro-cooling electronics. Flow visualization in micro-channels is an important aspect of fundamental understanding of flow phenomena associated to multiphase flow regimes [1]. Two-phase flow refers to the travel of fluids of both phases (liquid and gas) through a medium. The way in which the two phases interact is largely dependent on the configuration of the channel and flow properties [2]. Micro-channels are defined as having a diameter of less than $5 \mathrm{~mm}$. Two-phase flow through micro-channels is largely different than that through normal sized tubes. Firstly, this is due to an increase in the ratio of the surface area of the fluid flow to the volume they occupy [3]. Secondly, the flow occurs at much smaller Reynolds numbers, which indicates that the effects of viscous forces are more dominant than the effect of inertial forces [3]. Thirdly, the surface tension force has a significant effect on the flow patterns in microchannel [3]. Furthermore, the configuration of the micro-channel affects the flow pattern of the phases [2]. For example, in a horizontal tube, the effects of buoyancy stratify the fluid flow by pushing the gas flow above the liquid flow. Similarly, the effect of gravity will counteract to bring the liquid phase downwards causing the liquid phase to move towards the bottom of the channel.

\subsection{Flow types in straight horizontal micro-channels}

The flow regime or flow pattern in horizontal flow can be categorized into 6 main types: bubbly flow, plug flow, stratified flow, wavy flow, slug flow, and annular flow as indicated in Fig. 1. Based on the literature [4], [5], the flow patterns in microchannel can be explained as follows: in bubbly flow, the flow pattern shows a scattering of uniform gas bubbles flowing towards the top of the micro-channel. In plug flow, the gas phase occurs as 
a non-uniform bullet shape, also flowing at the top of the tube. Stratified flow occurs when the gas and liquid phases are separated and flow alongside each other, with the gas phase on the upper end of the tube. As the gas flow rate is increased, it allows the formation of waves on the liquid surface, which results in the wavy flow regime. Further increasing the gas velocity causes the wave formation to intensify, reaching the top of the microchannel and the flow regime turns to slug flow. As the velocity of the gas phase continues to increase, the liquid phase is filled with a gas core. The liquid phase remains on the surrounding walls of the tube while the gas phase remains on the inside.

The relevance of flow regime maps lies in the medical and computer engineering industries. This is due to the need for micro-heat exchangers and micro-coolers. Since the micro-channels in these devices are not transparent, it is not possible to find the flow regime in these channels by observation. Therefore, it is necessary to have a reliable reference in order to predict the flow regime based on known quantities of superficial air and water velocity. It is important to know the flow regime in heat exchangers due to that different patterns exhibit different heat transfer properties. For this reason, a flow regime map for wavy horizontal micro-channels was constructed in this study. This provides a contribution to the current field of investigating two-phase flow in micro-channels.

\subsection{Flow types in straight vertical micro-channels}

The flow regime or flow pattern in vertical flow can be categorized into 4 main types: bubbly flow, slug flow, wavy annular flow, and annular flow as indicated in Fig. 2. Based on the literature [7], the flow patterns in microchannel can be explained as follows: if the superficial gas and liquid velocity are low, the bubbly flow occurs in the microchannel. If the liquid velocity is low, larger bubbles are formed. If the liquid velocity is high, smaller bubbles are

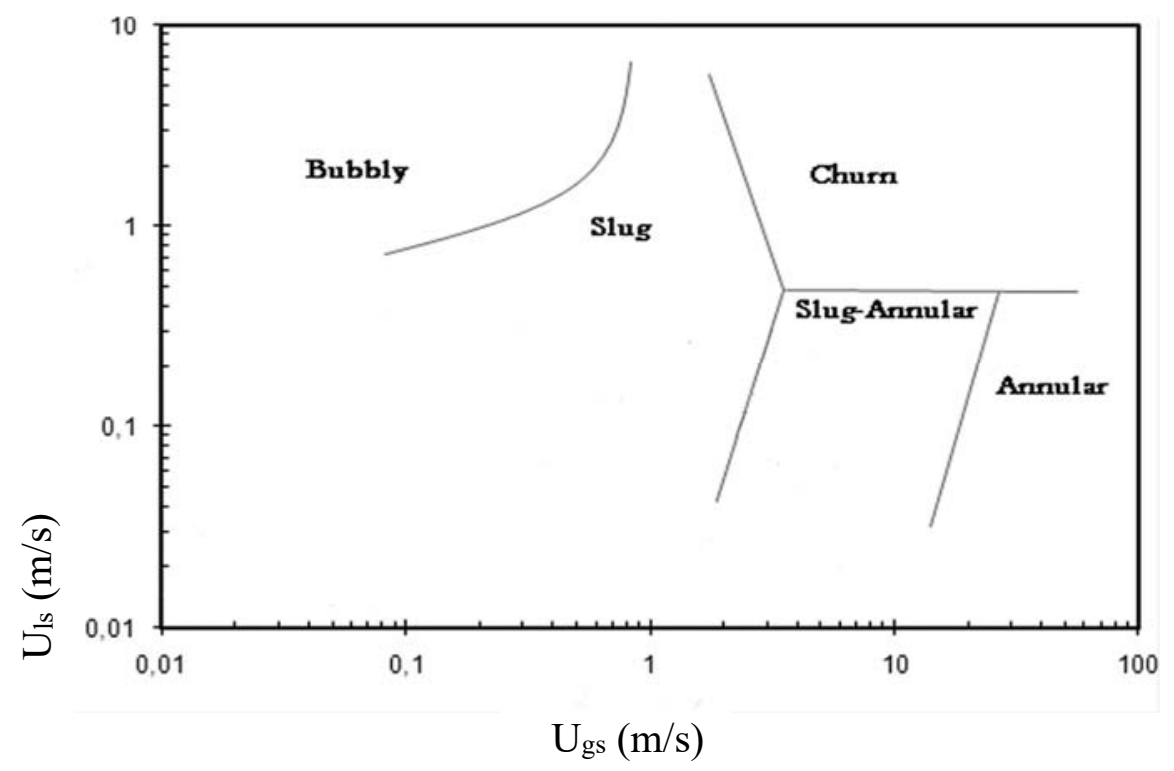

Figure 1: Typical flow regime map in horizontal microchannel [6]. Here, $U_{g s}$ is the superficial velocity of gas (air), and $U_{\mathrm{ls}}$ is the superficial velocity of liquid (water). 


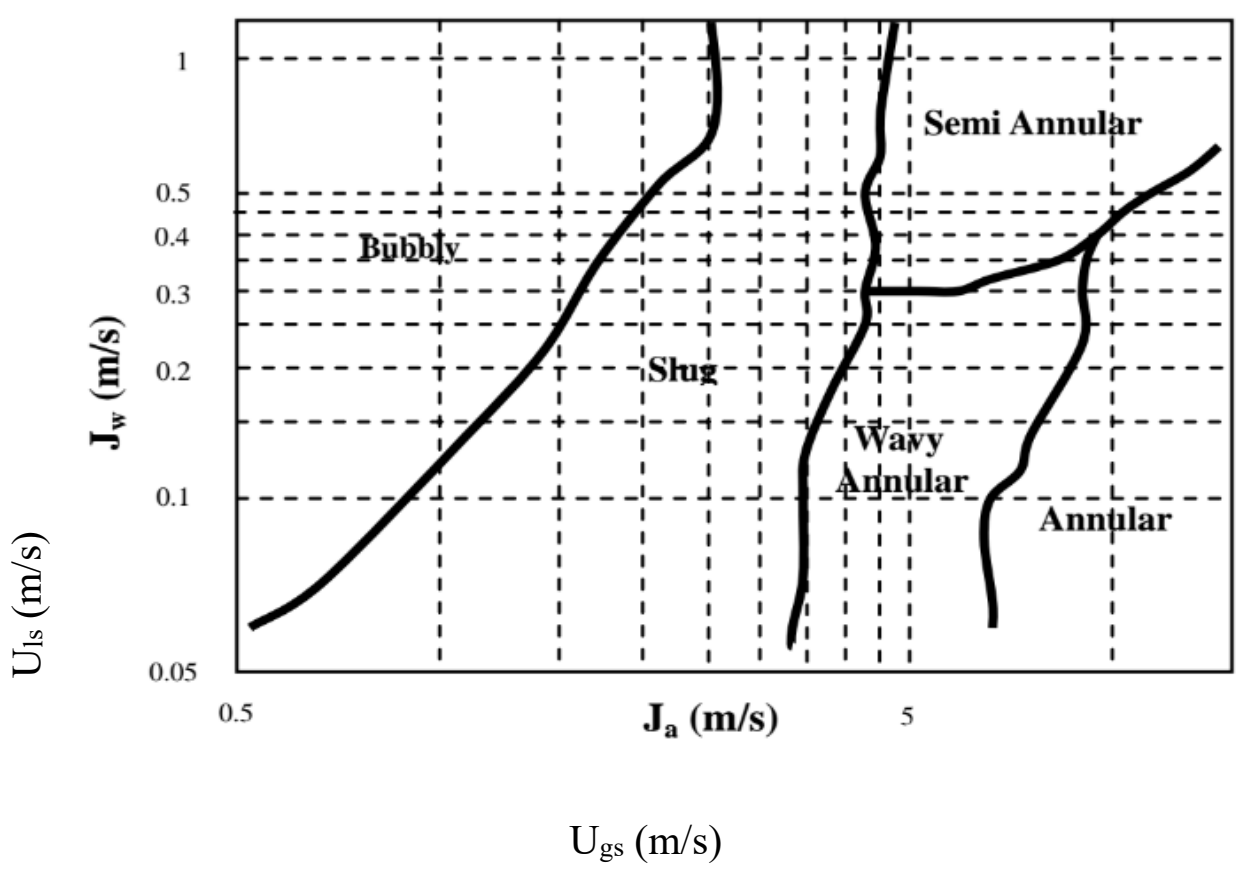

Figure 2: Typical flow regime map in vertical microchannel [1]. Here, $\mathrm{U}_{\mathrm{gs}}$ is the superficial velocity of gas (air), and $U_{1 s}$ is the superficial velocity of liquid (water).

formed due to turbulent splitting action. If the liquid and gas superficial velocity is increased, a large slug of water or a large pocket of air is formed in the channel. If superficial gas velocity is further increased, the liquid flows around the circumference of the pipe and gas in the core of the channel. Due to the dominant force in both gas and liquid phases, the liquid film in the channel wall exhibits wavy patterns. However, if the superficial gas velocity is too high, the flow regimes exhibit perfectly core annular flow in the channel.

\section{EXPERIMENTAL SETUP}

A schematic of the experimental set-up used in the experiment in presented in Fig. 3. The two inlets of the test specimen were connected to the air and water supply line and flow meters. In the outlet, the mixture of two phases go to an open tank where air goes back to the atmosphere and water goes back to the pump. The flow valves were used to vary the air and water flow rates during the experiment. The procedure of the experiment is as follows:

- The air and water flow rates for each reading were measured in $\mathrm{mm}$ in the flow meters.

- In order to quantify the flow rate of the water and air from the flowmeter readings, a specific constant is used, based on the flowmeter properties. This is shown in eqns (1) and (2). 
76 Computational and Experimental Methods in Multiphase and Complex Flow IX

$$
\begin{gathered}
\dot{\mathrm{Q}}_{\mathrm{w}}=\mathrm{k}_{\mathrm{w}} * \mathrm{~h}_{\mathrm{w}} * \frac{10^{-6}}{60}\left(\mathrm{~cm}^{3} / \mathrm{min}\right) \\
\dot{\mathrm{Q}}_{\mathrm{a}}=\mathrm{k}_{\mathrm{a}} * \mathrm{~h}_{\mathrm{a}} * \frac{10^{-6}}{60}\left(\mathrm{~cm}^{3} / \mathrm{min}\right)
\end{gathered}
$$

- The superficial water and air velocity is then found using the volumetric flow rate and the cross-sectional area of the channel as shown in eqns (3) and (4).

$$
\begin{aligned}
& \mathrm{V}_{\mathrm{w}}=\frac{\dot{\mathrm{Q}}_{\mathrm{w}}}{\mathrm{A}}(\mathrm{m} / \mathrm{s}) \\
& \mathrm{V}_{\mathrm{a}}=\frac{\dot{\mathrm{Q}}_{\mathrm{a}}}{\mathrm{A}}(\mathrm{m} / \mathrm{s})
\end{aligned}
$$

After optimizing the experimental conditions to meet the required image quality, videos of the flow for 63 runs were recorded in a computer and analyzed. Screenshots were taken from the videos and different flow conditions were studied visually to identify the flow pattern/regime for each data set.

\section{HIGH SPEED VISUALIZATION}

To obtain better quality images, a high-speed camera was used with a higher frame rate. This camera was called 'Photron SA3' is presented in Fig. 4.

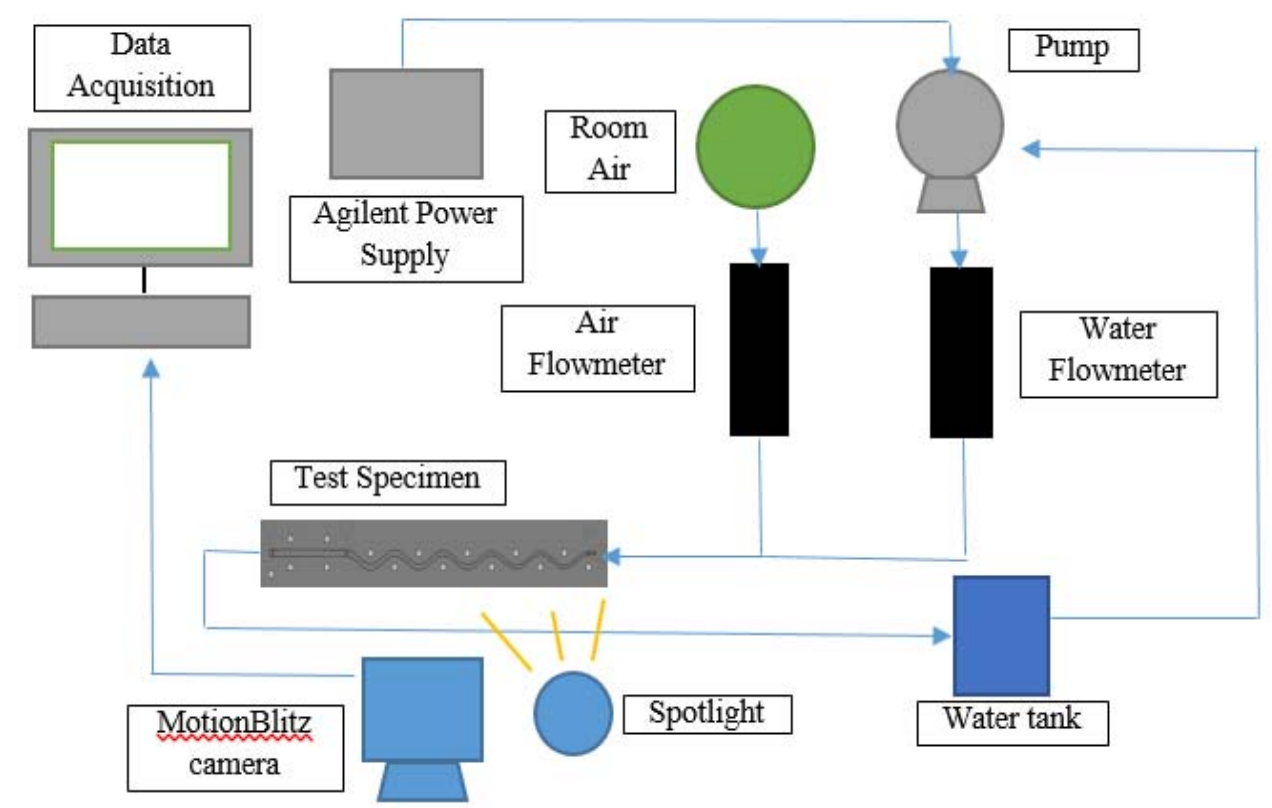

Figure 3: Schematic of experimental setup. 

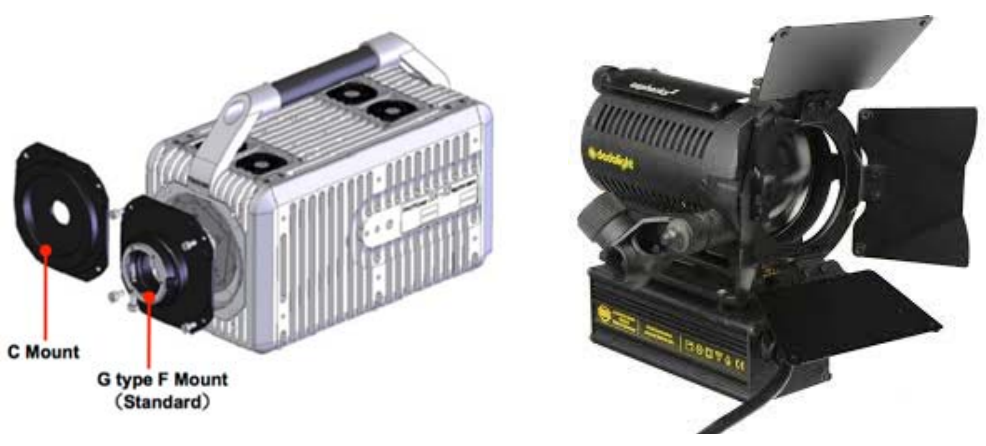

Figure 4: High-Speed camera and light source.

The camera was set up with a frame rate of 5000 frames per second. Two lights sources were used to illuminate the microchannel, one at the top of the channel and one straight on. The biggest challenge was to obtain detailed images of the flow while also minimizing the glare of the lights on the channel walls. Therefore, the lights had to be bright enough to illuminate the channel, but dim enough to reduce glare. A piece of paper was used as a diffuser to further reduce glare at the top and bottom of the channels.

\section{GRAPHICAL ANALYSIS}

The steps used in the graphical analysis are given as follows:

1. The superficial water velocity is plotted against the superficial air velocity for the number of experimental runs on the same graph. Each point on the graph belongs to a single run that has a certain water velocity and air velocity. The flow regime type for each of these runs is indicated on the plot to show the distribution of the flow regimes.

2. The data obtained was compared against pre-existing flow regime maps in published literature.

3. The mapping was analyzed, and it was deduced how well the collected data compares to pre-existing literature. The data collected was using a wavy microchannel, whereas the pre-existing literature was based on straight channels. Thus, at the final stage, a new pot was created based on the flow regimes obtained in this experiment putting superficial gas velocity in the $\mathrm{x}$-axis and superficial liquid velocity in the y-axis.

\section{RESULTS AND DISCUSSION}

The flow pattern from each recorded video is presented in Fig. 5 above. From these experiments, seven different flow patterns were observed in the wavy microchannel. These flow patterns were bubbly flow, slug flow, plug flow, stratified flow, wavy flow, churn (or semi-annular) flow and annular flow, respectively. The plane of all images in Fig. 5 is horizontal. The snapshot of different images was taken in different locations of the wavy channel. Thus, different curvature is evident in Fig. 5.

It can be observed that stratified flow occurs at low superficial water and air velocities. Increasing the superficial air velocity while keeping the superficial water velocity low causes 
a) Slug

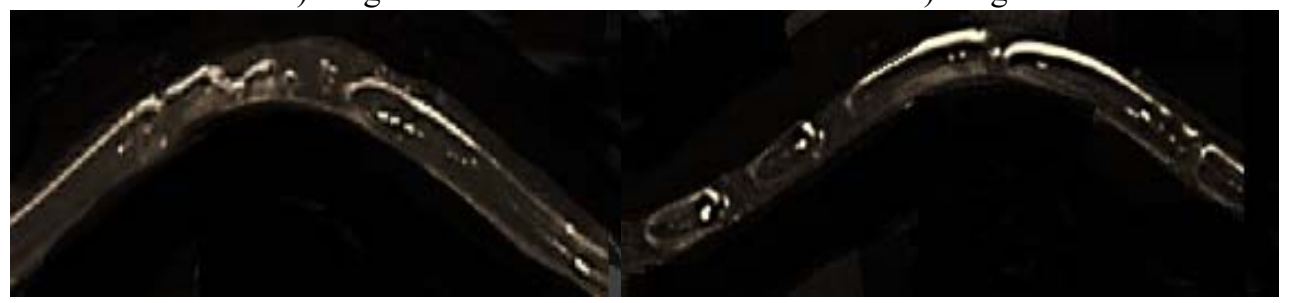

c) Stratified

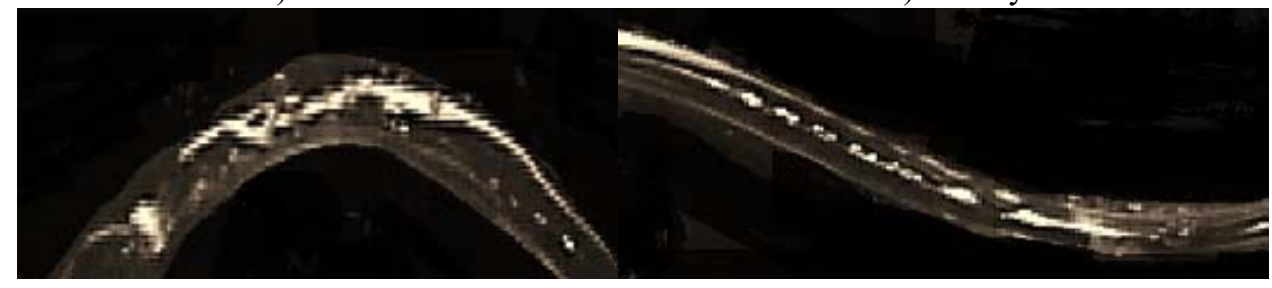

e) Wavy



Figure 5: Different flow regimes in wavy microchannel.

the flow to become wavy. This is also an agreement between both the theoretical flow maps. Moreover, increasing the superficial air velocity further results in annular flow. Slug flow tends to occur when higher water velocity and lower air velocity exist in the system. If the superficial water velocity continues to increase, the flow approaches bubbly flow. The main difference between the theoretical horizontal flow regime and horizontal wavy regime is the existence of the churn pattern. This is mainly considered to be a property of wavy channels as compared to completely straight horizontal channels. For this reason, the vertical flow properties of the wavy channel flow also need to be considered, though they are not a significant contributor to the flow pattern in horizontal wavy channels. While churn flow in the vertical microchannel flow map is occurred at low velocities of air and water, it occurs at relatively high superficial velocities of air and water for the wavy microchannel. This can be explained by the concept of momentum and how the flow direction switches. Flow also loses momentum at turns, especially when travelling upwards. The flow pattern from each recorded video in wavy microchannel were compared with the existing flow patterns within straight micro-channels in vertical and horizontal orientation. These comparisons are presented in Fig. 6. The channels have wavy structure in a horizontal plan. Both gravitational and inertial force affect the flow regime. The gravitational force wants to stratify the flow. Whereas, inertia force acts against the flow stratification and tries to provide disturbance in the flow with its momentum force. 
The data points based on different flow regimes (different air superficial velocity and different liquid superficial velocity) in wavy microchannel by visual observation were compared with the pre-existing flow regime maps for both horizontal and vertical positions. These existing maps in the literature pertained to horizontal and vertical flow within straight micro-channels. In wavy microchannel, flow patterns exhibit both horizontal and vertical micro-channel flow pattern since the flow first flows in the horizontal direction and afterward, the flow moves up in the curvature section. This unique shape of the wavy micro-channel brings the characteristics of a combination of horizontal flow regime map and vertical flow regime map. The data points based on different flow regimes in wavy microchannel by visual observation were first compared with the pre-existing flow regime map in horizontal straight microchannel as presented in Fig. 7. Due to the unique shape of the wavy microchannel, not all the data points correspond fully horizontal flow regime map. The highest discrepancy is observed in case of slug and plug flows. Finally, the data points based on different flow regimes in wavy microchannel by visual observation were compared with the pre-existing flow regime map in vertical straight microchannel as presented in Fig. 8. Similar to the previous case, not all the data points correspond vertical flow regime map. Again, the highest discrepancy is observed in case of slug and plug flow.

The flow pattern was determined for every data point, where a data point consisted of a superficial water velocity value and a superficial air velocity value. Data points were subsequently plotted on a superficial water velocity vs superficial air velocity map, and the flow pattern of each data point was displayed using the legend in Fig. 9. The graph was plotted on a log-log scale in order to provide a more accurate description of the distribution of the flow regimes. More experimental data points are required to obtain transition lines between the flow regimes maps.

\section{CONCLUSIONS}

There were seven different flow regimes identified in this experiment. These flow regimes were: Plug flow, Slug flow, Stratified flow, Churn flow, Annular flow, Wavy flow, and Bubbly flow. Seven different flow regimes were determined within the wavy micro-channel as the flow rates of water were varied from $29.1 \mathrm{~cm}^{3} / \mathrm{min}$ to $218.0 \mathrm{~cm}^{3} / \mathrm{min}$, and the air flow rate was varied from $313.3 \mathrm{~cm}^{3} / \mathrm{min}$ to $2350 \mathrm{~cm}^{3} / \mathrm{min}$. The flow regime map obtained from these data points provided a good insight into the distribution of flow regimes for different flow rates within a wavy horizontal micro-channel. Comparison with straight horizontal and vertical micro-channels revealed similarities and differences, which were expected since the micro-channel in question is not exactly straight. The wavy micro-channel exhibited trends of both horizontal flow regimes and vertical flow regimes, due to the flow within moving up and down along a sine way despite moving horizontally. The data presented in this paper could be considered as preliminary, where additional experiments are needed to construct a map with a practical range of the problem parameters.

\section{ACKNOWLEDGEMENT}

This paper was made possible by a UREP award [\#UREP18-108-2-045] from the Qatar National Research Fund (a member of The Qatar Foundation). The statements made herein are solely the responsibility of the authors. 

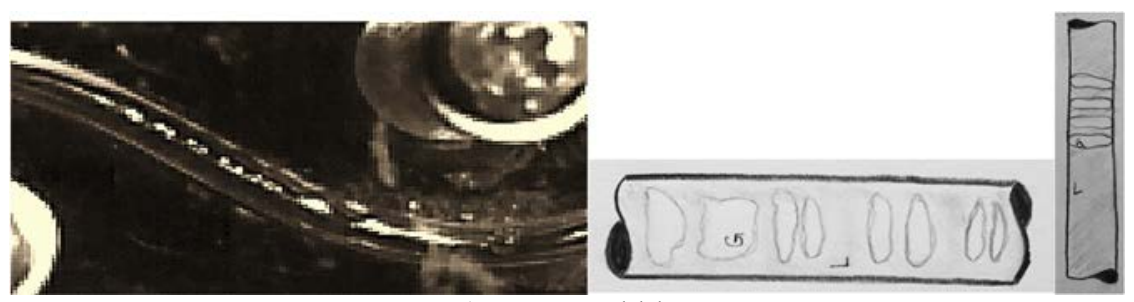

a)

Bubbly
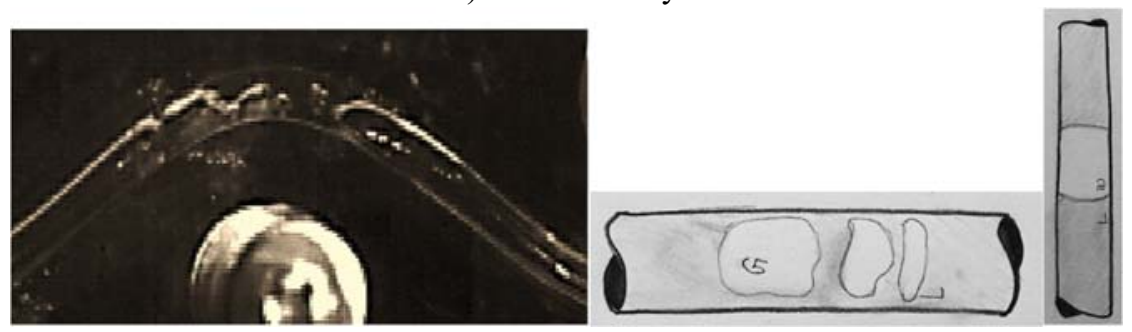

b)

Slug


c)

Annular

Figure 6: Comparison of different flow regimes in wavy, horizontal and vertical microchannel [1], [6].

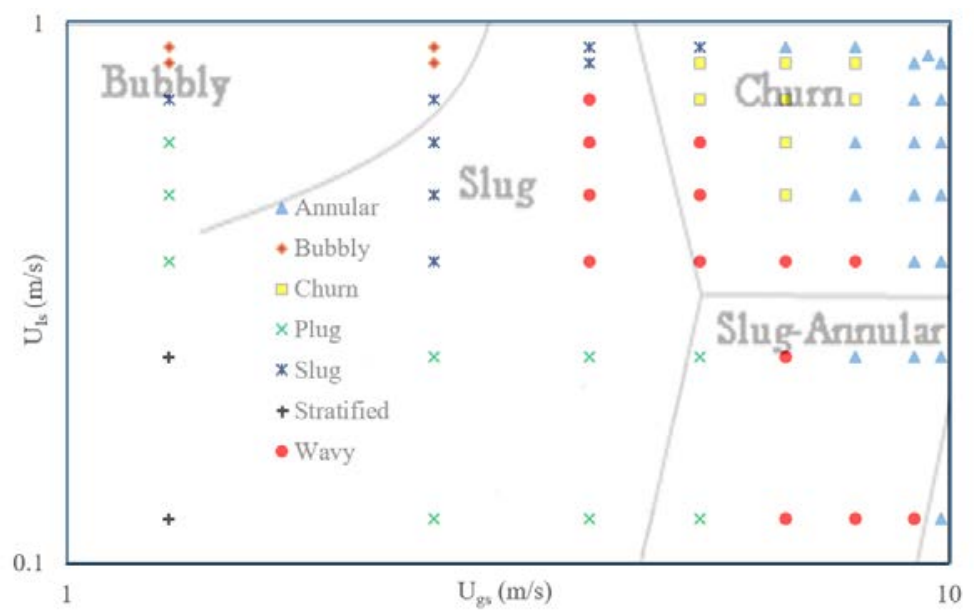

Figure 7: Mapping of horizontal straight micro-channel flow regimes onto horizontal wavy micro-channel flow regime map. 


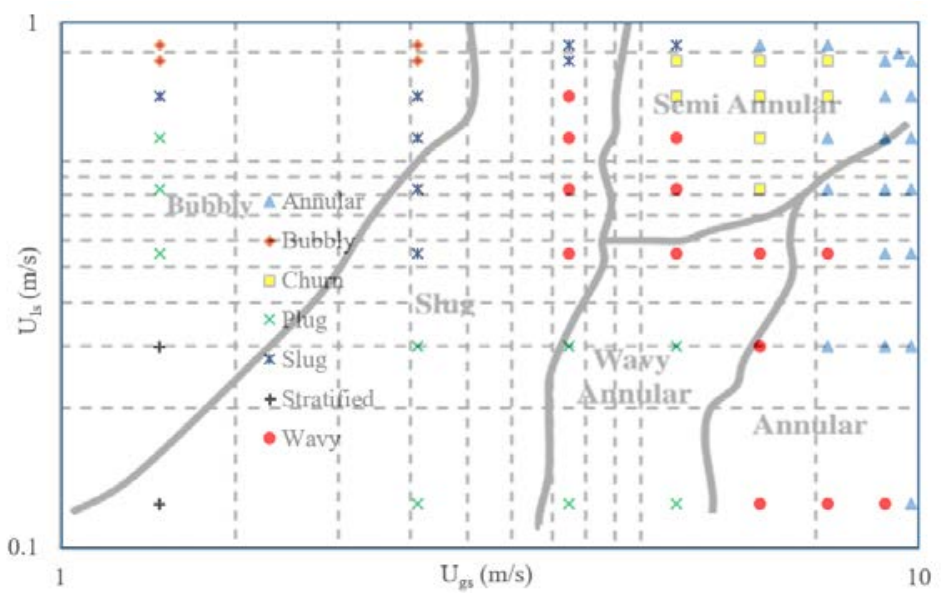

Figure 8: Mapping of vertical straight micro-channel flow regimes onto horizontal wavy micro-channel flow regime map.

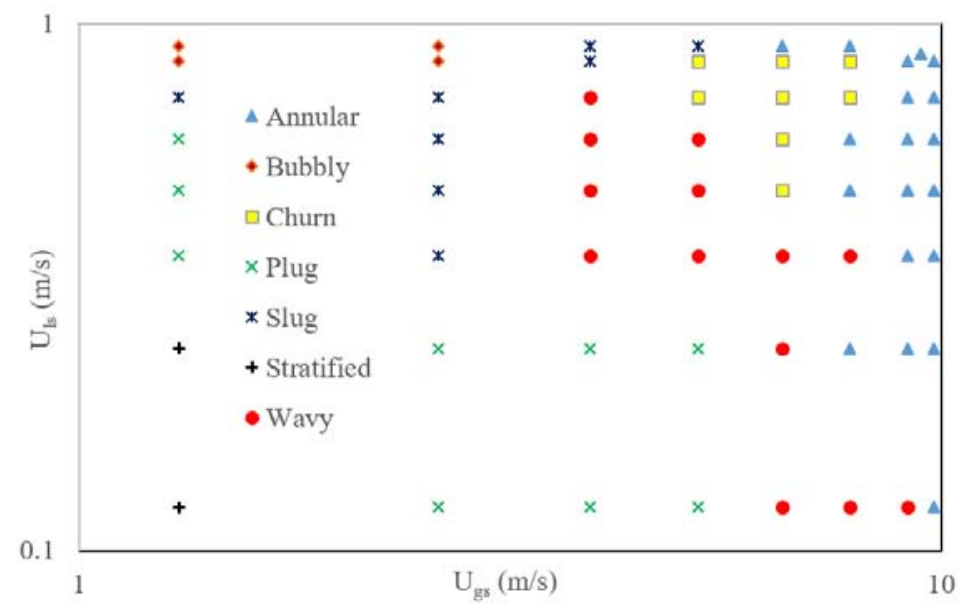

Figure 9: Flow regime map for horizontal air-water flow within a wavy micro-channel.

\section{REFERENCES}

[1] Hanafizadeh, P., Saidi, M.H., Nouri Gheimasi, A. \& Ghanbarzadeh, S., Experimental investigation of air-water, two-phase flow regimes in vertical mini pipe. Sci. Iran, 18(4), pp. 923-929, 2011.

[2] Cheng, L., Flow Patterns and Bubble Growth in Microchannels, Elsevier Inc., 2015.

[3] Rebrov, E.V., Two-phase flow regimes in microchannels. Theor. Found. Chem. Eng., 44(4), pp. 355-367, 2010.

[4] Agrawal, A., Two phase flow patterns and flow maps, 2010.

[5] Saisorn, S. \& Wongwises, S., Adiabatic two-phase gas-liquid flow behaviors during upward flow in a vertical circular micro-channel. Exp. Therm. Fluid Sci., 69, pp. 158$168,2015$. 
82 Computational and Experimental Methods in Multiphase and Complex Flow IX

[6] Ali, R., Palm, B., Martin-Callizo, C. \& Maqbool, M.H., Study of Flow Boiling Characteristics of a Microchannel Using High Speed Visualization. J. Heat Transf. ASME, 135(8), 2013.

[7] Thiangtham, P. et al., An experimental study on two-phase flow patterns and heat transfer characteristics during boiling of R134a flowing through a multi-microchannel heat sink. Int. J. Heat Mass Transf., 98, pp. 390-400, 2016. 